\title{
Do Computers Transform People into Women and Men?
}

\author{
BETTINA TÖRPEL \\ University of Bonn beetee@cs.uni-bonn.de
}

\begin{abstract}
This paper contains an outline activity theory concept of objectification, appropriation, and meaning/purpose. These concepts may fruitfully be applied in research on the construction of power relations including the gender hierarchy in the development and use of computer applications. I will present as an illustration a collection of tentative research questions regarding the development and use of groupware within a networked organization. These research questions might turn out to be inappropriate when confronted with the subjective experiences and interests of the developers, users, and researchers involved.
\end{abstract}

\section{INTRODUCTION}

The thought that what appears to be private is political has always been appealing to me. It suggests that:

1. Whatever we think or do occurs within a societal framework which suggest certain thoughts and actions. The societal framework does not determine what we think or do; we are likely to think and act in seemingly predetermined ways as long as we do not question and resist what is suggested. It is possible to resist and develop alternative modes of thinking and acting, if we have good reasons to do so. Strong reasons emerge in situations where we discover that what is habitually thought and done carries with it assumptions and tendencies that stabilize (societal) conditions detrimental to us.

2. We are capable of anticipating better (societal) conditions and of taking steps in the desired direction. But it is common to actively contribute 
to the continuation of detrimental conditions. Even small decisions have the potential to influence the future course society at large.

In the context of my research on the development and use of computer applications, there seemed to be a plausible link between these lines of thought and the activity theory concepts of objectification, appropriation and purpose/meaning'. I understand objectification to be the process and the product of incorporating meaning and purpose including assumptions into an artifact, and appropriation to be the process and product of creatively utilizing an artifact according to its purpose as subjectively perceived.

When theoretically framing 'gender' as a set of meanings created and constantly re-created by means of societal work, an application field seems to open up. One can look at gender as a set of meanings incorporated (objectified) into computer artifacts; at computer artifacts as possibly containing (objectifying) gender related assumptions and interests; and at computer artifacts in the processes of being introduced, becoming part of users' lives (becoming appropriated), possibly according to assumptions and interests pertaining to 'gender.'

In this contribution I will expand on this line of thought, describe directions for research I find promising, and present research questions from a research and development project on the design and use of groupware in a medium-size network organization.

The objective of the project is to look at relations between computer applications as structuring cooperative work on the one hand and new organizational structures on the other. ${ }^{2}$ Our focus lies on small and mediumsize network organizations. The co-development of work means and organizational structures seems to correspond to changing peculiarities in the market, a changing societal division of labor and therefore to a changing cooperative structure on the societal level. It seems to imply within the organization changing subjective possibilities and requirements, e. g. due to flat hierarchies or to changing teams.

Our primary application partner is a service company that provides consulting and training for example the moderation of group discussions or for software packages. This network consists of about 200 mainly freelance consultants and trainers who build teams of different sizes for specific projects [4]. About one forth of the network members are women. All executives are male; all secretaries are female. About three fifths of the men and one fifth of the women work in the business area of IT. A small company of up to eight male developers and one female secretary provided the software supporting the organizational communication and cooperation for the networked organization. Currently, this team is developing new software and the network organization is one of the prospective customers. 
My work in the project will comprise 1. analyzing the organizational groupware in use as a product for gender related functionalities 2 . observing how in the use of the organizational groupware gender issues arise and 3. monitoring the development of the future organizational groupware regarding steps objectifying 'gender.'

\section{COMPUTER APPLICATIONS AS MEANS LOCATED IN CHANGING LOCAL AND GLOBAL WORK ENVIRONMENTS}

I conceive of computer applications as artifacts mediating human actions toward objects or other subjects, as a means for achieving goals and realizing purposes. This reflects an understanding of applications consistent with activity theory as used in the fields of Computer Supported Cooperative Work, Human Computer Interaction and Participatory Systems Design [1]. The range of purposes need not be known or be conscious, either for those creating computer applications or for those using them. Computer applications are not ad-hoc means for the realization of immediate purposes, but rather serve generalized purposes in the sense that these purposes are present for a multitude of individuals and for multiple occasions. Computers serve the purpose of becoming specialized in the form of computer applications. Computer applications serve special purposes like text editing, displaying html-pages or controlling machines.

Daily routines have changed with new computer applications replacing or supplementing the set of means used to accomplish our work. These new means allow for and even enforce constantly changing work arrangements (in terms of routines, workplaces, contents of work, ways of cooperation, forms of organizations, forms of power distribution and execution).

Research questions related to this situation so far have been: How may the structure (including hierarchies and power structures) and development of the organization be described? What computer applications are used in the company? What functionalities are used? How are the computer applications used for different work activities? How do the functionalities of the employed computer applications and organizational features correspond to each other, assist each other or otherwise affect each other? How can we describe societal changes corresponding to organizational and technical changes: market changes, market requirements, the societal division of labor, the societal structure of cooperation and distribution of power? 


\section{ARTIFACTS AS OBJECTIFICATIONS}

Subjective phenomena like our perspectives, assumptions, or interests determine how we conceive of reality. These concepts are not just personal but immersed in and partial to facts like societal structures, hierarchies, power, societally suggested modes of thinking. Society, power, ideology are not 'located' in the outside world, but 'run through' us, via our bodies and minds and via how we think and act. Power (like oppression, ideology, hierarchy, struggle, contradiction) does not come from without. Nobody just 'innocently' builds and nobody just 'innocently' uses artifacts. We all are immersed in and part of societal power structures. These power structures are manifested in what we (are encouraged to) think and do and how we (are encouraged to) interpret reality. There is no way to escape being societal, being subject to interests, and being partial and subjective [7].

The subjective/societal assumptions 'within' us gain material influence with the creation of artifacts. They get 'built into' artifacts (process) and are 'contained within' them (result, product). By means of artifacts, the assumptions and interests unfold effects and make the assumptions and interests upon which the artifacts are based more plausible. Being in use often means that the artifacts are inescapable (for example as tools in work). The artifacts and their underlying assumptions and interests structure the thoughts and actions of many. One design option usually excludes many other design options. A decision for one design option in favour of a particular group can be a disadvantage to all other groups. Design and creation of artifacts is about inclusion and exclusion of perspectives, approaches and interests within the population of those potentially affected by the artifact. This is why artifacts and their underlying assumptions/categories are political $[12,5]$.

Using the example of bookkeeping standards, Winograd [13] explains that artifacts and their underlying categories often have facilitating and enabling effects. At the same time, they have the effect of limiting possibilities, disciplining, structuring, regulating, submitting, controlling, and exerting power $[5,8]$. Both aspects belong to artifacts and their underlying categories [3]. To pretend that artifacts, categories, assumptions and interests are neutral or even universal would either be ignorant or would be an especially subtle and potentially politically effective way of implementing certain interests or power structures.

What has been said about artifacts in general also refers to computer applications as particular kinds of artifacts.

Research questions in our project regarding the issue of objectification especially of power structures in the groupware developed for the network organization have been: What are relevant dimensions and interests 
'contained' in the groupware? Are there dimensions that are not initially obvious? Which groups are supported, which are neglected, and how is this done? How did these dimensions 'enter' the application? What steps did the software company take in the course of developing the application? What were the developing team's relevant explicit and implicit assumptions? What were relevant features of the context in which the application was introduced? Has the context changed? How are the existing functionalities appropriated? Are all the purposes, explicitly intended and implicitly objectified by the developers, realized by the users? Are 'hidden' purposes revealed in use? Are purposes added in use? Do users have the opportunity to broaden the range of functionalities in 'creative use'?

\section{THE GENDER HIERARCHY}

The 'gender' category strongly structures our lives. Even though 'gender' is experienced as 'natural' sets of responsibilities for most of us, this view is actively, massively and with great effort constructed and enforced by individuals in many societal locations. Even the experienced matter-offactness of the dimension of 'gender' has to be created with considerable effort and with the employment of serious threats. The production of 'gender' does not only occur in a 'pure' way, as relatively 'immediate' enactments and embodiments of 'femaleness' and 'maleness' closely related to the individuals and their bodies/expressions. It is rather important to acknowledge the production of 'gender' as an aspect of producing artifacts 'inescapable' and considered neutral. In the production as well as in the use of these artifacts we are prone to taking up and 'building in' 'gender' assumptions. These artifacts suggest thinking, talking, and acting along the lines of 'gender'. The meaning of 'gender' and the collective and subjective value of certain work activities which assure the further existence of the society, are closely related. For decades, 'being a woman' has meant doing work considered of low value while 'being a man' has meant doing work considered of high value. An implicit mutual attributing, if not defining relation, exists between woman and man and qualified and unqualified work [6]. However, this relation is by no means circular, but rather dynamic: In the course of history, 'gender' and the societal division of labor and cooperative structure continuously influenced each other and were influenced by other factors. 


\section{5. 'GENDER' (RE-) BUILT}

In the 'local' use and design of computer artifacts the 'global' societal reality of gender hierarchies is also permanently (re-)constructed, (re)structured, and (re-)designed. By being built into computer applications, gender (hierarchy) is incorporated into these systems, and remains in them as long as they are not redesigned. When they are used and appropriated, the assumptions 'reappear', form 'conditions' and become more plausible, because they are part of a usable means, and might be further developed in any direction. As long as 'gender' is a socially relevant category, hardly anyone is able to act indifferently towards the set of meanings making up 'gender.'

With the massive employment of information technologies as means for work, the societal division of labor itself has changed. At the same time, 'acting like a man' and 'acting like a woman' has changed. The meaning of 'gender' has changed with the emergence and propagation of computers. Computer applications have become work means in almost every workplace. Both sexes see women as responsible for the use of computer applications and men as responsible for the development of computer applications. This form of 'gender' enactment and gender hierarchy had never existed before, simply because computers and their applications are new artifacts. The labels of 'high level work' for development and of 'low level work' for use are inappropriate and do not reflect actual practice. Assumptions about 'development' and 'use' are problematic and do not help meet practical necessities [7]. In turn, an impact of the changed connotations of the 'gender' category on the societal division of labor, now structured by computer applications as means of production, has to be assumed.

Our research questions regarding these topics have been: How does the division of work within the organization of our application partner reflect common assumptions about 'gender?' Do female employees merely have knowledge of the use of computers while male employees have knowledge on how to design and program computer applications? Do men's and women's professional responsibilities within the organization correspond with their impact on, involvement with, understanding of and approach to the prospective organizational communication system? What are the gender related assumptions of the all male team providing the prospective organizational communication system? What assumptions and interests are objectified in the means (like tools for analysis and design, project organization, programming languages) used by the development team providing the future software? 


\section{CONSCIOUSLY RELATING GLOBAL AND LOCAL MEANINGS}

In human activities, the local (special and immediate) and the societal (general and mediated) always stand in relation to each other. Local actions are rooted in and react to societal meanings; and options locally viable in principle may become generalizable societal options.

One way of more consciously relating to societal meanings for local action, such as the development and use of computer applications, is to locally form alliances in which societal meanings are reconstructed. The results are 'informed hypotheses and interpretations' regarding societal meanings and structures. Applying these hypotheses to everyday phenomena prevents the individuals involved from being trapped in seemingly mattersof-course. A more conscious approach to societal reality (especially society's power structures) is likely.

That every person involved in the design and use of computer applications might actively contribute to the continuation of the gender hierarchy, even if this is detrimental to her or him, should not only be a revealing or (self-) accusing statement. The understanding of our potential active yet unconscious involvement should result in efforts to reconstruct where we exactly contribute to the continuation of the dimension of 'gender' via such actions, artifacts and concepts. Finding, trying and evaluating alternative yet viable concepts and modes of action are integral parts of this kind of research.

A promising research strategy starts with problems experienced, failures, and limited influence about subjectively relevant (societal) resources, like the perceived inability to use a particular computer application. As soon as good reasons exist to acquire a more global understanding of a particular field, individuals find a group of people who experience similar limits and a similar urge to understand and change the situation. Those involved acquire relevant qualifications in a process of common and mutual learning: knowledge of the subject matter in question, suitable research concepts and adequate research methods.

At the same time they reveal limits of influence on relevant conditions, and if the experiences regarding the situation differ, they 1 . hypothetically form typologies of the situations experienced (definitely not typologies of persons, because this would focus the attention of assumed personal qualities instead of relations between individuals and their conditions) and 2. collect all modes of behavior in these situations as experienced or seen so far. In the course of the research, individuals on one hand continuously reconstruct the situations in question; on the other hand they form hypotheses about new and better ways of acting in these situations. The new forms of behavior are 
employed in 'controlled practice'. Some situations may require better strategies of acting within the boundaries of the situation; other situations may require the change of the situation itself. Hypothesis testing or evaluation here means comparing the experienced quality of life (supposedly corresponding to influence about relevant societal resources) considering different strategies of action. This is the so-called science-of-the-subject research strategy as proposed by Critical Psychology, a particular approach to activity theory $[2,9]$.

The appropriateness of research questions presented in previous sections of this paper for finding out more about the objectification and appropriation of 'gender' in the development and use of groupware, will become evident in the course of a science-of-the-subject research process as described in this section. The method was developed and has been mostly applied within the social sciences. Little experiences exist for its applicability to the design of artifacts $^{3}$. Science-of-the-subject strategies draw on the assumption that research participants have a common interest. For software development in 'traditional' enterprises this is not the case, but the interests are rooted in conflicts between capital and labor. In new forms of organizations - like networked organizations - interests and conflicts evolve along different lines. Many workers are to a certain extent employees and entrepreneurs at the same time: on the one hand they may use the infrastructure (like groupware) of the networked organization and receive their payment from the network instead of being directly paid by a customer. On the other hand they may own their own work means, rely on finding their customers, and have the choice of working freelance within the network or as an independent individual.

Adapted versions of science-of-the-subject research methods will probably have certain similarities to techniques already employed in participatory approaches to systems development, e. g. moderation techniques. For the questions of individual and typical contributions to the gender hierarchy the radical use of subjectivity as in subject-of-the-science approaches might yield generalizable results.

\section{ENDNOTES}

1. These concepts are interpreted in diverse ways within activity theory. This is my conclusion after having read texts by authors like Leontiev, Holzkamp, Tolman, Engeström, Bannon, Bødker, Nardi, and Kuutti.

2. The project "Integrated Cooperation Management in Network Organizations" (Integriertes Kooperationsmanagement in Netzwerkorganisationen, InKoNetz) is funded by the ADAPT Initiative of the European Commission.

3. When computers were first introduced for typists in the administration of the city-state of Bremen, Germany, Winker $[10,11]$ initiated a participatory subject-science process. 
Topics included changes in the structure of the work of the typists, promotion prospects into qualifies administrative positions instead of dead-end jobs, computer-related qualifications and the use of computers.

\section{REFERENCES}

1. Bødker, S. (1990). Through the interface - A human activity approach to user interface design. Hillsdale, NJ: Lawrence Erlbaum Associates.

2. Holzkamp, K. (1983). Grundlegung der Psychologie. Frankfurt a. M.: Campus.

3. Orlikowski, W. J. (1995). Categories: concept, content, and context. In: Computer Supported Cooperative Work 3, 73-78.

4. Rittenbruch, M., Kahler, H., \& Cremers, A. B. (1998). Supporting Cooperation in a Virtual Organization. In: Proceedings of the International Conference on Information Systems (ICIS) '98 (December 13-16), 30-38.

5. Suchman, L. (1994a). Do categories have politics? In Computer Supported Cooperative Work 2, 177-190.

6. Suchman, L. (1994b). Supporting articulation work: aspects of a feminist practice of technology production. In: Adam, A., E. Green, J. Emms \& J. Owen (Eds.), Women, work and computerization: Breaking old boundaries - building new forms. Proceedings of the IFIP TC9/WG9.1 fifth international conference on women, work and computerization, Manchester, U.K., 2-5 July, 1994. Amsterdam: Elsevier, 7-21.

7. Suchman, L. (1994c). Working relations of technology production and use. In: Computer Supported Cooperative Work (CSCW), 2, 21-39.

8. Suchman, L. (1995). Speech acts and voices: Response to Winograd et al. In: Computer Supported Cooperative Work (CSCW), 3, 85-95.

9. Tolman, C. W. \& Maiers. W. (Eds.), (1991). Critical psychology: Contributions to an historical science of the subject. Cambridge, England: Cambridge University Press.

10.Winker, G. (1995). Büro. Computer. Geschlechterhierarchie. Frauenförderliche Arbeitsgestaltung im Schreibbereich. Opladen: Leske + Budrich.

11. Winker, G. ([1993]1996). Frauenforschung im Spannungsfeld zwischen Praxis und institutionalisierter Wissenschaft. In: Sonderausgabe 10 Jahre Frauenarbeit und Informatik, 59-66.

12. Winner, L. ([1980] 1986). Do artifacts have politics? In: Winner, L. (Ed.), The whale and the reactor. A search for limits in an age of high technology. Chicago: Chicago University Press, 19-39.

13. Winograd, T. (1994). Categories, disciplines, and social coordination. In Computer Supported Cooperative Work (CSCW), 2, 191-197. 